\title{
Validasi Metode Penentuan Kalsium Pada Sampel Air Filter Layer Secara Automatik Titrasi di Balai Konservasi Borobudur
}

\author{
Yorfan Ruwindya dkk. \\ Program Studi DIII Analis Kimia FMIPA Universitas Islam Indonesia \\ Email : yruwindya.ak@gmail.com
}

\begin{abstract}
Abstrak : Telah dilakukan validasi metode penentuan kalsium dalam sampel air filter layer dengan metode automatik titrasi. Air yang mengandung kalsium dianalisis dengan menggunkan alat automatik titrasi yang berprinsip pada titrasi potensiometri. Titer yang digunakan adalah larutan EDTA. Dalam penelitian ini dilakukan validasi metode dengan parameter akurasi, presisi, linieritas, batas deteksi dan batas kuantitatif. Nilai persen perolehan kembali (\%Recovery) untuk sampel T2H sebesar 107,5286\% dan sampel S2C sebesar 105,1429\%. Nilai persen relatif standar deviasi (\%RSD) untuk sampel T2H sebesar 1,8581\% dan sampel S2C sebesar 2,0076\%. Hasil linieritas metode menunjukkan nilai koefisien korelasi sebesar 0,998. Nilai batas deteksi dari alat diperoleh sebesar 0,6858 $\mathrm{mg} / \mathrm{L}$ dan batas kuantitatif sebesar 2,2862 $\mathrm{mg} / \mathrm{L}$. Berdasarkan hasil yang diperoleh, menunjukkan bahwa metode ini dapat digunakan secara rutin pada penentuan kalsium dalam sampel air dengan alat automatik titrasi karena metode valid.
\end{abstract}

Kata kunci: automatik titrasi, LOD, LOQ, linieritas, akurasi dan presisi

\begin{abstract}
Has been validated method of determination of calcium in the water sample filter layer with automatic titration method. Water that contains calcium analyzed by using means of automatic titration principled on potentiometric titration. Titer used is EDTA solution. In this research, the method validation parameters of accuracy, precision, linearity, limit of detection and quantitative limits. Value percent recovery (\% Recovery) for T2H samples and samples of $107.5286 \% 105.1429 \%$ of S2C. Value percent relative standard deviation (\% RSD) for sample T2H of $1.8581 \%$ and $2.0076 \%$ of the sample S2C. The results show the method linearity correlation coefficient of 0.998 . Values obtained detection limits of the instrument of $0.6858 \mathrm{mg} / \mathrm{L}$ and a quantitative limit of $2.2862 \mathrm{mg} / \mathrm{L}$. based on the results obtained, show that this method can be used routinely in the determination of calcium in water samples by means of automatic titration because the method is valid.
\end{abstract}

Keywords: automatic titration, LOD, LOQ, linearity, accuracy and precision

\section{PENDAHULUAN}

\section{A. Latar Belakang}

Untuk melindungi Candi Borobudur yang merupakan salah satu warisan dunia (World Heritage), telah dilakukan dua kali pemugaran terhadap candi tersebut, yaitu pada tahun 1907-1911 dan tahun 19731983. Pasca pemugaran kedua terus dilakukan upaya pelestarian terhadap candi Borobudur. Kelestarian Candi Borobudur sangat dipengaruhi oleh dua faktor utama, yaitu faktor internal dan faktor eksternal. Faktor internal meliputi aspek bahan dan aspek konstruksi bangunan candi. Sedangkan faktor eksternal yang mempengaruhi kelestarian Candi Borobudur adalah faktor lingkungan, baik yang bersifat biotis (lumut, algae dan jasad renik lainnya) dan yang bersifat abiotis (panas matahari, hujan, kelembaban dan sebagainya).

Pada pemugaran kedua Candi Borobudur dibuat sebuah lapisan yang disebut sebagai filter layer (lapisan penyaring). Lapisan penyaring (filter layer) dibuat untuk menahan perembesan air yang mengalir ke permukaan luar (Boniyem, 2013). Hal ini masih dirasa belum efektif karena air masih bisa mempengaruhi kelestarian bangunan candi, karena adanya kandungan-kandungan mineral dalam air. Salah satu kandungan mineral yang terdapat dalam air adalah kalsium. Kalsium yang berasal dari dalam air jika merembes ke bangunan candi, akan menambah kadar kalsium dalam bangunan candi karena umumnya bangunan candi terbuat dari batuan andesit yang sudah memiliki kadar kalsium yang cukup tinggi. Hal ini akan menimbulkan efek terbentuknya endapan garam pada permukaan bangunan candi dan endapan garam ini akan membentuk lapisan putih yang dapat merusak relief candi.

Metode yang digunakan untuk menentukan kandungan kalsium dalam air filter layer ini adalah dengan mengikuti acuan pada prosedur Manual Practical Titration Metrohm, yaitu metode titrimetri yang ternyata sama dengan SNI 06-6989.13-2004 tentang cara uji kalsium (Ca) dalam air dengan metode titrimetri. Metode ini merupakan metode rutin yang digunakan di 
laboratorium dan akan digunakan pada alat yang berbeda yaitu autotitrator, sehingga perlu diuji validitasnya atau dilakukan validasi terhadap metode uji tersebut. Parameter yang ditentukan untuk melakukan validasi tersebut antara lain adalah batas deteksi, batas kuantitatif, presisi, dan akurasi. Tujuan dari penelitian ini adalah untuk memvalidasi metode pengujian penentuan kalsium dalam sampel air.

\section{B. Metode}

Penentuan konsentrasi kalsium dalam air filter layer pada Candi Borobudur ini menggunakan alat automatik titrasi Metrohm 848 Titrino Plus. Bahan yang digunakan sebagai standar pada penelitian ini antara lain larutan standar baku kalsium dengan konsentrasi $1000 \mathrm{mg} / \mathrm{L}$ dan larutan Titriplex III atau Na2EDTA dengan konsentrasi 0,01 M. Acuan prosedur penelitian ini mengacu pada SNI 06-6989.13-2004 tentang cara uji kalsium (Ca) dalam air dengan metode titrimetri. Validasi metode dilakukan karena metode yang digunakan ini biasanya untuk model titrasi konvensional dan akan diterapkan pada titrasi otomatis atau titrasi potensiometri, maka metode ini perlu dilakukan validasi metode.

Tabel 1. Volume titrasi dan konsentrasi sampel $\mathrm{T} 2 \mathrm{H}$ air filter layer

\begin{tabular}{ccc}
$\begin{array}{c}\text { KODE } \\
\text { SAMPEL }\end{array}$ & $\begin{array}{c}\text { VOLUME TITRASI } \\
(\mathrm{mL})\end{array}$ & $\begin{array}{c}\text { KONSENTRASI } \\
(\mathrm{mg} / \mathrm{L})\end{array}$ \\
\hline $\mathrm{T} 2 \mathrm{H} 1$ & 1,4511 & 23,26 \\
$\mathrm{~T} 2 \mathrm{H} 2$ & 1,4567 & 23,35 \\
\hline $\mathrm{T} 2 \mathrm{H} 3$ & 1,4887 & 23,87 \\
\hline $\mathrm{T} 2 \mathrm{H} 4$ & 1,5173 & 24,33 \\
\hline $\mathrm{T} 2 \mathrm{H} 5$ & 1,472 & 23,6 \\
\hline $\mathrm{T} 2 \mathrm{H} 6$ & 1,4605 & 23,41 \\
\hline $\mathrm{T} 2 \mathrm{H} 7$ & 1,4354 & 23,01 \\
\hline
\end{tabular}

Tabel 2. Volume titrasi dan konsentrasi sampel S2C air filter layer

$\begin{array}{ccc}\begin{array}{r}\text { KODE } \\ \text { SAMPEL }\end{array} & \begin{array}{r}\text { VOLUME TITRASI } \\ (\mathrm{mL})\end{array} & \begin{array}{c}\text { KONSENTRASI } \\ (\mathrm{mg} / \mathrm{L})\end{array} \\ \text { S2C } 1 & 1,1867 & 19,02 \\ \text { S2C 2 } & 1,1829 & 18,96 \\ \text { S2C 3 } & 1,1766 & 18,86 \\ \text { S2C 4 } & 1,2072 & 19,35 \\ \text { S2C 5 } & 1,1721 & 18,79 \\ \text { S2C 6 } & 1,2212 & 19,58 \\ \text { S2C 7 } & 1,1481 & 18,41\end{array}$

Tabel 3. Penentuan \%RSD dan \%KV Horwitz sampel T2H air filter layer

\begin{tabular}{|lllll|}
\hline NO & $\begin{array}{r}\text { KONSENTRASI } \\
\text { (mg/L) }\end{array}$ & SD & \%RSD & KV HORWITZ \\
\hline 1 & 23,26 & & & \\
\hline 2 & 23,35 & & & \\
\hline 3 & 23,87 & & & \\
\hline 4 & 24,33 & 0,4375 & 1,8581 & 9,9454 \\
\hline 5 & 23,6 & & & \\
\hline 6 & 23,41 & & & \\
\hline 7 & 23,01 & & & \\
\hline$X$ & 23,5471 & & & \\
\hline
\end{tabular}

Tabel 4. Penentuan \%RSD dan \%KV Horwitz sampel S2C air filter layer

\begin{tabular}{|ccccc|}
\hline NO & $\begin{array}{r}\text { KONSENTRASI } \\
\text { (mg/L) }\end{array}$ & SD & \%RSD & KV HORWITZ \\
\hline 1 & 19,02 & & & \\
\hline 2 & 18,96 & & & \\
\hline 3 & 18,86 & & & \\
\hline 4 & 19,35 & 0,3814 & 2,0076 & 10,2722 \\
\hline 5 & 18,79 & & & \\
\hline 6 & 19,58 & & & \\
\hline 7 & 18,41 & & & \\
$X$ & 18,9957 & & & \\
\hline
\end{tabular}

Alat automatik titrasi ini sendiri juga memiliki beberapa kelebihan dan kekurangan. Kelebihan dari alat automatik titrasi antara lain dapat meneliti dengan cepat, tingkat akurasi baik, dan tingkat presisi baik. Kekurangan dari alat ini adalah alat ini tidak mampu menganalisis konsentrasi suatu sampel yang kecil di bawah 0,2 ppm, sehingga alat ini hanya cocok untuk menganalisis konsentrasi yang tinggi.

\section{PEMBAHASAN}

Hasil percobaan penentuan kandungan kalsium dalam sampel air filter layer dapat dilihat pada Tabel 1 dan Tabel 2. Nilai konsentrasi kalsium dalam sampel telah dikonversi dari volume titran yang diperoleh untuk mentitrasi sampel.

Penentuan kandungan kalsium dalam sampel dihitung dengan rumus sebagai berikut:

EP1 adalah volume titrasi $(\mathrm{mL}), 0,4008 \mathrm{mg} / \mathrm{mL}$ adalah faktor konversi $\mathrm{Ca}(1 \mathrm{~mL}$ Na2EDTA $0,01 \mathrm{M}=$ 0,4008 mg), 1000 adalah faktor konversi dari mL menjadi $\mathrm{L}$, dan C00 adalah volume sampel yang dititrasi (mL). 


$$
\mathrm{Ca}(\mathrm{mg} / \mathrm{L})=\frac{\mathrm{EP} 1 \times 0,4008 \times 1000}{\mathrm{C} 00}
$$

Kandungan kalsium yang terdapat dalam sampel air filter layerT2H berkisar antara $23,35 \mathrm{mg} / \mathrm{L}$ sampai $24,33 \mathrm{mg} / \mathrm{L}$ dengan rata-rata $23,5471 \mathrm{mg} / \mathrm{L}$. Sedangkan, untuk sampel air filter layer S2C berkisar antara $18,79 \mathrm{mg} / \mathrm{L}$ sampai 19,58 mg/L dengan rata-rata 18,9957 mg/L.

Presisi dari metode yang digunakan untuk menganalisis kandungan kalsium dalam air filter layer diperoleh setelah menganalisis sampel dengan tujuh kali preparasi. Presisi ditentukan dari nilai simpangan baku relatif. Nilai tersebut dapat ditentukan dengan menggunakan rumus sebagai berikut:

$$
\mathrm{KV}(\%)=\frac{\mathrm{SD}}{\overline{\mathrm{X}}} \mathrm{X} 100 \%
$$

Keterangan:

SD : standar deviasi

KV : koefisien variasi (RSD, simpangan baku relatif) $\mathrm{X} \quad$ : rata-rata pengukuran

Hasil dari penentuan presisi pada analisis yang dilakukan terhadap sampel air filter layer dapat dilihat pada Tabel 3 dan Tabel 4.

Berdasarkan nilai persen relatif standar deviasi (\%RSD) dan nilai KV horwitz yang diperoleh, maka dapat dikatakan bahwa repitabilitas dari pengukuran sampel T2H dan S2C air filter layer diterima.

Pengukuran akurasi dari metode yang digunakan ini dilihat dari uji persen perolehan kembali. Nilai persen perolehan kembali dilakukan dengan metode adisi (penambahan baku) yaitu dengan menambahkan sejumlah larutan standar ke dalam larutan sampel (spiking). Selisih hasil antara kandungan larutan yang di-spike dengan kandungan sampel tanpa spike dibandingankan dengan kadar yang sebenarnya (hasil yang diharapkan). Perhitungan perolehan kembali dapat ditetapkan dengan rumus sebagai berikut:

$\%$ Perolehan kembali $($ recovery $)=\frac{(\mathrm{C} 1-\mathrm{C} 2)}{\mathrm{C} 3} \mathrm{X} 100 \%$

\section{Keterangan:}

C1 : konsentrasi dari analit dalam campuran contoh + sejumlah tertentu analit

C2 : konsentrasi dari analit dalam contoh
C3 : konsentrasi dari analit yang ditambahkan kedalam contoh

Hasil dari penentuan persen perolehan kembali (recovery) pada analisis yang dilakukan terhadap sampel air filter layer dapat dilihat pada Tabel 5 dan Tabel 6 .

Berdasarkan Tabel 5 dan Tabel 6, terlihat bahwa nilai persen perolehan kembali (\% recovery) pada sampel T2H air filter layer berkisar antara 99,7\% sampai 112,9\% dengan nilai rata-rata sebesar 107,5286\%, sedangkan, pada sampel S2C air filter layer nilai persen perolehan kembali (\% recovery) yang diperoleh berkisar antara 99,3\% sampai $111 \%$ dengan nilai rata-rata sebesar $105,1429 \%$. Berdasarkan hasil nilai persen perolehan kembali atau \% recovery yang diperoleh untuk setiap sampel, maka dapat disimpulkan bahwa akurasi dari metode yang digunakan dalam analisis penentuan kandungan kalsium pada sampel air filter layer ini baik.

Penentuan linieritas dari metode digunakan lima konsentrasi kalsium yang berbeda yaitu dari konsentrasi $2 \mathrm{mg} / \mathrm{L}, 4 \mathrm{mg} / \mathrm{L}, 6 \mathrm{mg} / \mathrm{L}, 8 \mathrm{mg} / \mathrm{L}$, dan $10 \mathrm{mg} / \mathrm{L}$. Hasil pengukuran kalsium dalam larutan tersebut dapat dilihat

Tabel 5. Penentuan $\%$ recovery pada sampel $\mathrm{T} 2 \mathrm{H}$ air filter layer

\begin{tabular}{cccc}
$\begin{array}{c}\text { KONSENTRASI } \\
\text { SAMPEL NON } \\
\text { SPIKE,B (mg/L) }\end{array}$ & $\begin{array}{c}\text { KONSENTRASI } \\
\text { SAMPEL SPIKE, } \\
\text { A (mg/L) }\end{array}$ & $\begin{array}{c}\text { KONSENTRASI } \\
\text { TARGET, } \\
\text { C (mg/L) }\end{array}$ & $\begin{array}{c}\% \\
\text { RECOVERY }\end{array}$ \\
\hline 23,26 & 34,3 & 10 & 110,4 \\
23,35 & 34,3 & 10 & 109,5 \\
23,87 & 34,3 & 10 & 104,3 \\
24,33 & 34,3 & 10 & 99,7 \\
23,6 & 34,3 & 10 & 107 \\
23,41 & 34,3 & 10 & 108,9 \\
23,01 & 34,3 & 10 & 112,9 \\
& Rata-Rata & & 107,5286 \\
\hline
\end{tabular}

Tabel 6. Penentuan \% recovery pada sampel S2C air filter layer

\begin{tabular}{cccc}
$\begin{array}{c}\text { KONSENTRASI } \\
\text { SAMPEL NON } \\
\text { SPIKE,B (mg/L) }\end{array}$ & $\begin{array}{c}\text { KONSENTRASI } \\
\text { SAMPEL SPIKE, } \\
\text { A (mg/L) }\end{array}$ & $\begin{array}{c}\text { KONSENTRASI } \\
\text { TARGET, } \\
\text { C (mg/L) }\end{array}$ & $\begin{array}{c}\% \\
\text { RECOVERY }\end{array}$ \\
\hline 19,02 & 29,51 & 10 & 104,9 \\
18,96 & 29,51 & 10 & 105,5 \\
18,86 & 29,51 & 10 & 106,5 \\
19,35 & 29,51 & 10 & 101,6 \\
18,79 & 29,51 & 10 & 107,2 \\
19,58 & 29,51 & 10 & 99,3 \\
& $18,4129,51$ & 10 & 111 \\
& Rata-Rata & & 105,1429 \\
\hline
\end{tabular}


Tabel 7. Konsentrasi terukur larutan standar $\mathbf{C a}$

$\begin{array}{cc}\text { KONSENTRASI TEORITIS } & \begin{array}{c}\text { KONSENTRASI TERUKUR } \\ (\mathrm{mg} / \mathrm{L})\end{array} \\ 2 & 2,44 \\ 4 & 4,04 \\ 6 & 6,43 \\ 8 & 8,67 \\ 10 & 10,44\end{array}$

Tabel 8.Batas deteksi dan batas kuantitatif

\begin{tabular}{|c|c|}
\hline PARAMETER & NILAI \\
\hline Intersep & 0,215 \\
\hline Slope (S) & 1,0315 \\
\hline Koefisien korelasi & 0,998 \\
\hline Koefisien determinasi & 0,9961 \\
\hline
\end{tabular}

pada Tabel 7.

Kurva linieritas diperoleh dengan membuat kurva hubungan antara konsentrasi teoritis sebagai sumbu $\mathrm{X}$ dan konsentrasi terukur sebagai sumbu Y, sehingga nilai regresinya dapat ditentukan. Nilai dari regresinya dapt dilihat pada Tabel 8 dan kurva linieritas dapat dilihat pada Gambar 1.

Nilai batas deteksi dan batas kuantitatif ditentukan dengan mengukur nilai larutan standar $\mathrm{Ca}$ pada lima konsentrasi yang berbeda yaitu $2 ; 4 ; 6 ; 8 ; 10$ $\mathrm{mg} / \mathrm{L}$. Hasil dari pengukuran kemudian dibuat kurva antara konsentrasi secara teoritis dengan konsentrasi yang terukur. Batas deteksi dari metode ini diperoleh sebesar 0,6858 $\mathrm{mg} / \mathrm{L}$ dan batas kuantitatif diperoleh sebesar 2,2862 mg/L, dapat dilihat pada Tabel 8 .

\section{DAFTAR PUSTAKA}

BKB, 2014, Kompleks Candi Borobudur (Borobudur Temple Compounds), Borobudur, Indonesia: Balai Konservasi Borobudur (BKB).

Boniyem, 2013, Verifikasi Metode Uji Penentuan Kandungan Timbal pada Sampel Air Filter layerCandi Borobudur dengan Spektrofotometer Serapan Atom, Laporan PKL, FMIPA, Yogyakarta: Universitas Islam Indonesia (UII).

Patel, D., Patel, S., Parmar, Y., Chauhan, K., Sannigrahi, P., Rawat, A.S., dan Vardhan, A., 2013, A Novel Potentiometric Titration Method for

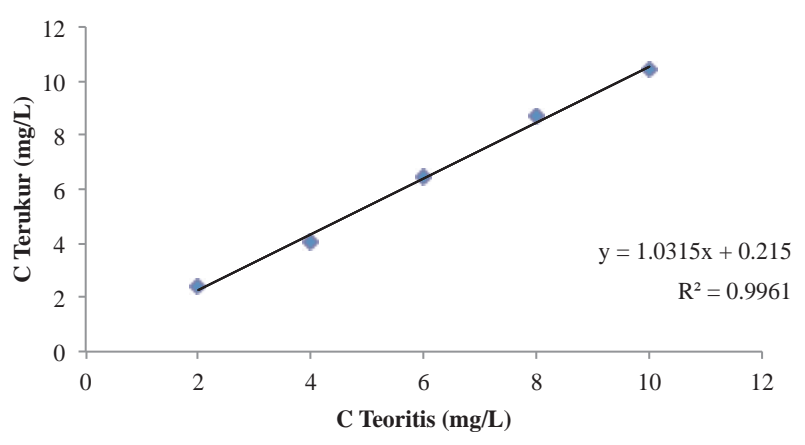

Gambar 1. Kurva linieritas

Tabel 8. Batas deteksi dan batas kuantitatif

\begin{tabular}{ll} 
PARAMETER & NILAI \\
\hline Standar deviasi & 0,2358177 \\
Slope (S) & 1,0315 \\
LOD & $0,6858 \mathrm{mg} / \mathrm{L}$ \\
LOQ & $2,2862 \mathrm{mg} / \mathrm{L}$ \\
\hline
\end{tabular}

\section{PENUTUP}

Metode penentuan kalsium dengan metode titrasi potensiometri telah di validasi dengan parameter presisi, akurasi, linieritas, batas deteksi dan batas kuantitatif. Nilai dari persen perolehan kembali dan persen temu balik serta koefisien determinasi menunjukan bahwa metode yang digunakan baik dan sensitif. Metode yang digunakan valid. Hal ini berdasarakan nilai yang diperoleh dari semua parameter validasi. Metode ini dapat digunakan secara rutin pada penentuan kalsium dengan alat automatik titrasi.

Quantitative Determination Bromide Content in Doxorubicin Hydrochloride, IJPRR, Vol. 2. No. 9, 10-15.

Riyanto, 2014, Validasi \& Verifikasi Metode Uji: Sesuai dengan ISO/IEC 17025 Laboratorium Pengujian dan Kalibrasi, Edisi 1, Yogyakarta: Deepublish.

Soekmono, 1983, Pelita Borobudur Laporan Kegiatan Proyek Pemugaran Candi Borobudur Seri A No. 5: Laporan Kerja Proyek Pemugaran Candi Borobudur 1972/1973, Jakarta: Departemen Pendidikan dan Kebudayaan RI. 